\title{
Klinefelter's Syndrome with a Presumptive Deleted X Chromosome
}

\author{
JOHANNES NIELSEN \\ From the Institute of Psychiatry, Arhus State Hospital Risskov, Denmark
}

Klinefelter's syndrome with a deleted X chromosome has previously only been reported in two cases with chromosome mosaicism, one with $47 / 48$ $\mathrm{XXY} / \mathrm{XXXY}$ described by Crawfurd (I96I), and one with $47 / 46 / 46 \mathrm{XxY} / \mathrm{Xx} / \mathrm{XY}$, described by De La Chapelle (1963); both are doubtful cases of $X$ deletion as the first had only one sex chromatin body and the last was chromatin negative.

Crawfurd (I96I) described a 30-year-old patient with thalassaemia, Klinefelter's syndrome, and chromosome mosaicism. The sex chromosomes were $\mathrm{XXY}(47)$ in 54 cells, and $\mathrm{XXxY}(48)$ in 13 cells. Buccal smear was chromatin positive, but no cells had more than one sex chromatin body.

In a survey of sex chromosome abnormalities among 1,758 patients with severe mental retardation De La Chapelle (1963) found an I8-year-old boy with an IQ of 30 , who was first reported as having 49 chromosomes and a sex chromosome constitution of $\mathrm{XXXxY}$ with deletion of the major part of the long arm of one $X$ chromosome in IO5 out of $I 10$ cells, but later interpreted as a case of $49 \mathrm{XXXXY}$ and autosomal translocation 6-12/4-5 (A. De La Chapelle, 1965, personal communication).

Valencia, Sonnenschein, Bur, and de Lozzio (1964) described a case of Klinefelter's syndrome with chromosome mosaicism of the type $\mathrm{XxY}$ (47) in 21 cells, $\mathrm{Xx}(46)$ in 15 cells, and $X Y(46)$ in 21 cells. The extra small chromosome described as deleted $\mathrm{X}$ long arm is, however, judged from the karyotype published, more similar to the chromosomes in the $13-15$ group, and it is either total deletion of the long arm of one $\mathrm{X}$ or trisomy 13-15. The authors mention, however, that the patient fits better clinically in the Klinefelter group than in the autosomal 13-I5 trisomy group. No chromatin bodies were found in buccal smears on this patient.

\section{Materials and Methods}

In a nuclear sexing study of patients in a mental hospital, among 1,570 males 16 cases of chromatin-

Received October 4, 1965. positive Klinefelter's syndrome have been found. The oral smears were Feulgen-stained, and in all chromatinpositive males the chromosomes were studied in leucocyte culture according to the technique described by Moorhead, Nowell, Mellman, Battips, and Hungerford (1960).

\section{Case Report}

Chromosome Pattern. Of the Is chromatinpositive patients with Klinefelter's syndrome, one was found to have the sex chromosome constitution of $47 / 46$ $\mathrm{XxY} / \mathrm{XY}$. In all, 70 cells were counted and analysed, 63 had 47 chromosomes and an XxY, one had 46 chromosomes and an XxY, but lacked a small acrocentric autosome, and 6 had 46 chromosomes and an $\mathrm{XY}$ sex-chromosome complement. In all the cells with 47 chromosomes, the extra chromosome was the size of chromosome No. 16, as seen in Fig. I and 2. Feulgenstained buccal smears showed $14 \%$ chromatin positive cells. With $14 \%$ chromatin positive cells in buccal smears and clinical manifestation of Klinefelter's syndrome, this extra chromosome was most probably an $\mathrm{X}$ chromosome with a presumptive deletion of the major part of the long arms.

Clinical History. The patient was 54 years old. He was admitted to a mental hospital because of confusion. Six weeks before admission he was hit by a car. He was unconscious for Io days after the accident and operated for epidural haematoma. Six weeks after admission to the mental hospital he died from pneumonia, which did not respond to antibiotic treatment. $\mathrm{He}$ never was oriented, able to recognize his family or friends, or carry out any conversation while he was in the mental hospital.

He was the fifth of 7 children; the two youngest brothers died when a few months old, probably of pneumonia. A sister died at 25 years of tuberculosis. Two brothers and one sister are healthy, married, and have children. The patient's father was 31 years old and his mother 33 years old, when he was born. His mother died of tuberculosis at the age of 37 , and his father died at the age of 62 of pneumonia. There were no mental disorders and no inheritable somatic disorder of any kind in the near relatives, but a maternal uncle was an epileptic. His mother was healthy during pregnancy, 


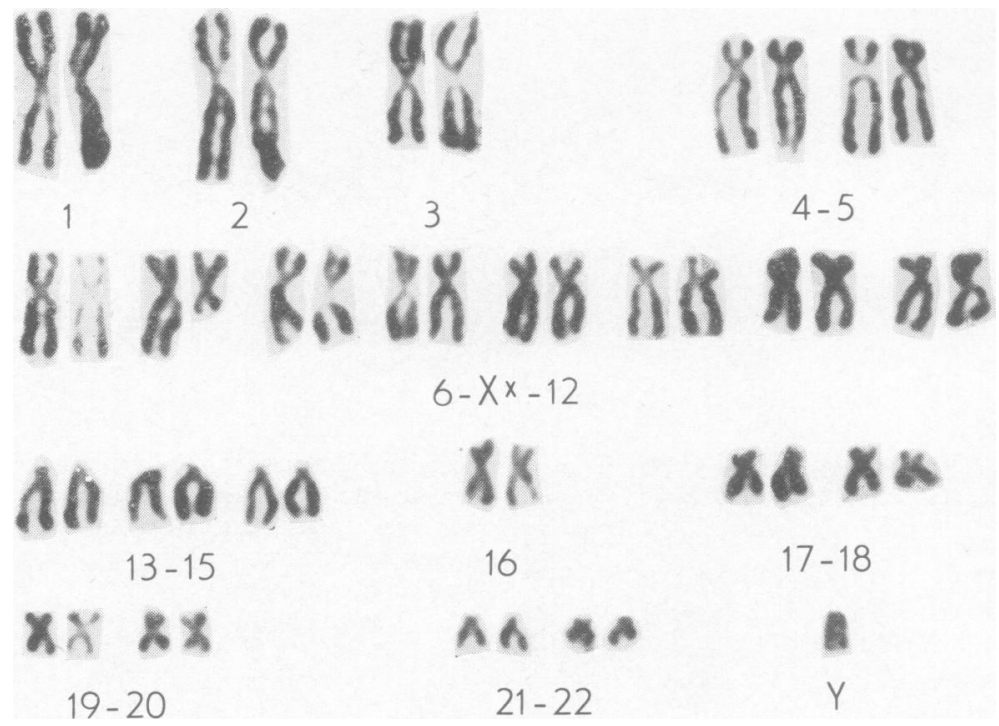

FIG. I. Karyotype with deleted X.

and delivery was normal. He walked at the age of 3 and talked at the age of 4 . He started school at the age of 7 , but was considered mentally defective and was admitted to an institution for mentally retarded at II years. At that age he understood conversation and was fairly good at talking. He could dress and eat and be occupied with simple manual work. He was quiet and good-natured, but was easily upset. At the age of

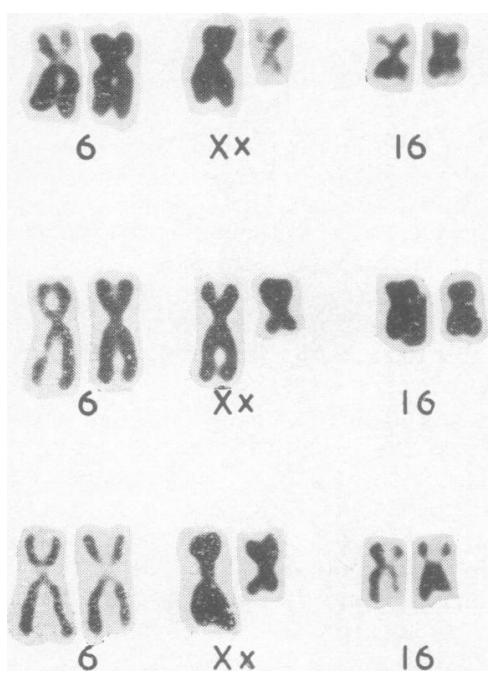

Fig. 2. Chromosome pair No. 6, X, deleted X, and 16 from three karyotypes.
I I he did not have the most elementary knowledge of spelling, reading, or arithmetic.

At 17 he was described as childish, honest, and reliable but very impetuous, and with a strong temper. He used to bite his nails and he was nervous. From the age of I9 he was most often described as mean, naughty, lazy® and unreliable. From the age of 25 he had sexual rela $\overrightarrow{7}$ tions with several of the female patients, and he ofters masturbated openly. At the age of 32 his IQ was 78 with great variations in the subtests. It was at that time concluded by the psychologist who tested the patientthat he was definitely above the IQ level of 75 , and that his inability to read and write was most probably due to the lack of systematic teaching, and, to some extent tof decreased vision not recognized till the age of 20 . It was concluded that it was character defects more than intellectual defects that characterized the patient.

At the age of $4 \mathrm{I}$ he was discharged from the institutiom for the mentally defective on the grounds of his intelligence level. From the time of discharge until admission to the state hospital at the age of 54 the patient hade. difficulties in taking care of himself. From the age of 50 he has spent most of his time in a social welfare institution. At the age of $5 \mathrm{I}$ he got a suspended sentences of 4 months in prison for indecency to a 6-year-old girl $\mathrm{N}$ At that time psychological testing with WAIS, TAT, ando Rorschach showed a verbal IQ of 82, and a performance IQ of 84. His thinking was concretizing, childish, and primitive. His ability for independent mental work wases poor and he appeared naive, he overrated himself, and did not concentrate. His adaptation to reality was poor and he functioned as a weak person with poor control of his impulses.

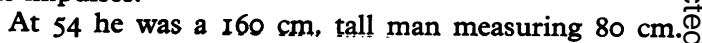


from sole to pubis, and with a span of $71 \mathrm{~cm}$. His head was comparatively small, and his ears were slightly irregular of shape. Beard growth was scanty. There was no chest hair and very scanty axillary hair. Pubic hair distribution was feminine, and there was practically no hair growth on the extremities. There was no gynaecomastia. The penis was of normal size, but the testes were soft and measured $10 \mathrm{~mm}$. from pole to pole. The right testis was in the inguinal canal. The extremities were thin with poorly developed musculature. Radiograph of the spine showed a previous fracture in the first lumbar vertebra together with moderate spondylosis, and no osteoporosis. Radiograph of both hands showed the third metacarpal bone on both hands to be shorter than normal. Routine laboratory examinations revealed no abnormality. Protein-bound iodine was low, and the electrocardiogram was of low voltage.

\section{Discussion}

It is of interest to compare our patient with other cases of Klinefelter's syndrome with 47 chromosomes XXY without deletion. Our patient differed to a certain extent from the rest of the 20 cases of chromatin-positive Klinefelter's syndrome, diagnosed in our laboratory, in the following respects. He was smaller than any of our other 20 patients; he showed more marked personality defects, but his sexual activity was more pronounced than any of the other 20 cases. The sex chromatin percentage in buccal smear was $14 \%$, which is less than usually found in patients with Klinefelter's syndrome. This correlates with the percentage of sex chromatin in females with deletions of the major part of the long arm of one X (Jacobs, Harnden, Court Brown, Goldstein, Close, MacGregor, Maclean, and Strong, 1960; De Grouchy, Lamy, Yaneva, Salomon, and Netter, I96I ; Gropp, von Krosigk, Odunjo, Zander, Kern, and Buntru, 1963). This might indicate that a factor for sex chromatin manifestation is located in the long arm of $X$. The size of the sex chromatin mass was within normal range. Jacobs et al. (1960) found that the sex chromatin mass was smaller than usual in deletion of the major part of the $X$ in a female patient with triple-X syndrome.

A reason for discrepancies in the size of sex chromatin bodies in patients with deletion $\mathrm{X}$ might be that only the region adjacent to the centromere is inactivated. The size of the sex chromatin body would then depend on the extension of the deletion in relation to the centromere. Another reason for sex chromatin bodies of normal size in the present case might be that the deleted $X$ was not the inactivated $X$ as it must have been in the case with smaller sex chromatin bodies described by Jacobs et al. (I960).

\section{Summary}

A case of Klinefelter's syndrome with deletion of the major part of the long arm of $\mathrm{X}$ is reported with clinical and cytogenetic data.

\section{REFERENCES}

Crawfurd, M. D'A. (196I). Chromosomal mosaicism in a case of Klinefelter's syndrome with thalassaemia. Ann. hum. Genet., 25, I53.

De Grouchy, J., Lamy, M., Yaneva, H., Salomon, Y., and Netter, A. (196I). Further abnormalities of the $\mathbf{X}$ chromosome in primary amenorrhoea or in severe oligomenorrhoea. Lancet, $2,777$.

De La Chapelle, A. (1963). Sex chromosome abnormalities among the mentally defective in Finland. F. ment. Defic. Res., 7, 129.

Gropp, A., von Krosigk, H., Odunjo, F., Zander, J., Kern, E., and Buntru, G. (I963). Chromosomenmosaike bei primărer Amenorrhoe. Klin. Wschr., 41, 345.

Jacobs, P. A., Harnden, D. G., Court Brown, W. M., Goldstein, J., Close, H. G., MacGregor, T. N., Maclean, N., and Strong, J. A. (1960). Abnormalities involving the $\mathrm{X}$ chromosome in women. Lancet, I, 1213.

Moorhead, P. S., Nowell, P. C., Mellman, W. J., Battips, D. M., and Hungerford, D. A. (1960). Chromosome preparations of leukocytes cultured from human peripheral blood. Exp. Cell Res., 20, 6r3.

Valencia, J. I., Sonnenschein, C., Bur, G., and de Lozzio, C. B. (1964). A new type of chromosome mosaicism related to the Klinefelter syndrome. Lancet, $1,143$. 
student, it should prove acceptable to geneticists not actually working in this discipline, for the book is beautifully organized and the text refreshingly concise. It supplements most usefully the corresponding sections in Whitehouse's book, reflecting as it does things under discussion as well as knowledge fully established.

The subtitle of Dr. and Mrs. Beadle's book, The Language of Life, is, 'An introduction to the science of genetics'. The book is, however, more than that. It is a lucid account of biology in general, starting with the origin and evolution of life, a subject to which some 50 pages are devoted. Mendelian genetics is discussed in another quarter of the book. The rest of the text is an authoritative exposition of the biochemical aspects of modern genetics, presented in a fluent popular style with illustrations that are fresh and illuminating. Easily read and highly informative, this book is a model of what an introductory book should be.

The Foundations of Genetics by F. A. E. Crew is mainly an account of classical genetics. About half the text is a critical tribute to Mendel and the pioneers of Mendelism. The later developments are briefly indicated. In scope and presentation this little book is eminently suitable for the general reader.

In the Origins of Mendelism the Librarian of the Botany School at Oxford gives an excellent account of the mental climate in which Mendel's work was done. Recognition of Koelreuter's work on the sexuality of plants carried out in the second half of the 18th century, and of the subsequent studies of the plant hybridists, only emphasizes the immense advance Mendel initiated by introducing qualitative criteria into the study of heredity. While accepting Fisher's contention that Mendel carried out his experiments to confirm a rigidly thought-out hypo- thesis, Dr. Olby refutes the suggestion that the actual observations were not as painstaking. There is a good discussion on the difficulties that Darwinism faced as a result of Darwin's fear that natural selection would be discounted once it was accepted that sudden jumps occur in Nature. 'Natura non facit saltum' was a ragged banner in a confused fight. In that fight the part that Galton played was not quite so clear as is suggested by the author: in fact there is excessive veneration of Galton, who is described as 'probably the most original biologist of the century.' The riddle why Mendel was overlooked for a generation still remains, even if it is true that the fundamental work carried out during those lost years made Mendel's contribution more meaningful to an age that was begining to ask questions to which he had given a remarkably lucid answer-an answer. which itself posed meaningful questions. Dr. Olby's study thus extends to the origins of present-day genetics as well as to those of Mendelism. The extensive appendices giving extracts from the relevant material discussed in the text add to the value of this important study. The frank discussion of De Vreies' equivocal acknowledgement of Mendel is refreshing and welcome.

Lüth's study is a popular account of the development and present state of human genetics. Adequate and accurate, it goes beyond the usual limits of such expositions by dealing rather extensively with possible future developments-leaning in this heavily on the Ciba symposium on Man and his future, which was held in London in 1962. A more individual contribution is the grim and factual chapter on the collapse of academic values in genetics and anthropology in German universities during the twenties and thirties, a collapse which presaged Nazi Germany's descent into barbarism.

\section{Corrigendum}

Klinefelter's Syndrome with a Presumptive Deleted X Chromosome, by Johannes Neilson. Volume 3, p. 139.

Opening paragraph, lines 5 and 6, for de la Chapelle (1963), read, Valencia, Sonnenschein, Bur, and de Lozzio (1964). 